\title{
University of Montana
}

ScholarWorks at University of Montana

Spring 2018

\section{An Exploration into Archival Descriptions of LGBTQMaterials}

Erin Baucom

University of Montana, Missoula

\section{Let us know how access to this document benefits you.}

Follow this and additional works at: https://scholarworks.umt.edu/ml_pubs

Part of the Library and Information Science Commons

\section{Recommended Citation}

Baucom, Erin, "An Exploration into Archival Descriptions of LGBTQ Materials" (2018). Mansfield Library Faculty Publications. 30. https://scholarworks.umt.edu/ml_pubs/30

This Article is brought to you for free and open access by the Mansfield Library at ScholarWorks at University of Montana. It has been accepted for inclusion in Mansfield Library Faculty Publications by an authorized administrator of ScholarWorks at University of Montana. For more information, please contact scholarworks@mso.umt.edu. 


\title{
An Exploration into Archival Descriptions of LGBTQ Materials
}

\author{
Erin Baucom
}

\begin{abstract}
While traditional archives have successfully diversified collecting scopes to include materials from marginalized communities, archivists have yet to examine whether the descriptions of these materials appropriately represent the communities of origin. In an effort to determine how discoverable LGBTQ collections are and if the terms used to describe LGBTQ individuals might be inaccurate and possibly harmful to the LGBTQ community, this article compares terms used by LGBTQ history project Web sites to describe gender and sexual identities to terms used in traditional archives to portray those same identities. This comparison reveals that the terms in finding aids are general and in some cases outdated versus the diverse and modern language that appears on LGBTQ history project Web sites. The article ends with recommendations to explore collaborations with the LGBTQ community through personal relationships, creating subject guides, and providing an avenue for those viewing finding aids to suggest improvements to reconcile those differences.
\end{abstract}

(C) Erin Baucom. (cc) BY-NC

\section{KEY WORDS}

Archival description, LGBTQIA+, Community archives, Access, Finding aids, Minority stress, Identity and language 
$\mathrm{T}$ erminology is a crucial aspect of identity formation and affirmation. The language chosen by society to categorize parts of identity, positive and negative, have an impact on how individuals construct and internalize their own identities. In the past, the number of terms for sexual and gender identities were limited, and only a small percentage were socially acceptable. All of these socially acceptable terms describe the sexuality and genders with which a majority of society identified: heterosexual, male, and female. ${ }^{1}$

Over the last century, the LGBTQ ${ }^{2}$ (lesbian, gay, bisexual, transgender, and queer) community has internally created new terms for the now-acknowledged diversity of sexual and gender identities. Since the conclusion of World War II, the LGBTQ community has campaigned to make these terms visible and accepted by society. An abbreviated history of this begins with the "homophile" movement in the 1950s. In the 1960s and 1970s, the community campaigned to remove "homosexual" from the psychiatric diagnostic manual when "gay" was the preferred community term. From the 1990s to the present, the word "queer" has become the rallying point for activists as an attempt to encourage the acceptance of an umbrella term that includes as much of the sexuality and gender continuums as possible. ${ }^{3}$

The more diverse and accepted language available to individuals when they are constructing their identities, the more likely they will accept their gender and sexual identities in a positive manner. It is crucial to the continued wellbeing of individuals to be able to see the social majority use and accept these identifiers. ${ }^{4}$ Dr. Ilan Meyer, an expert in health issues in minority populations, developed a model to show how being part of a social minority affects the health and well-being of minority individuals. Dr. Meyer labeled this model "minority stress." In his work, one of the key stressors for sexual and gender minorities is ". . . feedback from others that is incompatible with one's self-identity." This minority stress, when compounded with the everyday stress of work, family life, and so on, can cause an increase in the likelihood that the individual will experience negative psychological consequences including anxiety, depression, and suicidal thoughts or actions. One way an individual may ameliorate minority stress is through accepting the minority identity and forming bonds within the minority community as a buffer to the stress imposed by the social majority. ${ }^{6}$

Archives play a role in this continual process of identity formation and acceptance because archives hold and preserve some of the primary source materials that help elucidate the history of the LGBTQ community. Being able to access this history helps combat feelings of isolation and contests negative perceptions and misrepresentations of the LGBTQ community. ${ }^{7}$ The terms used by archivists when arranging and describing LGBTQ materials affect how researchers find and perceive these collections. Archivists who do not use the terms LGBTQ community members use to identify themselves when describing 
these collections render the materials more difficult to find. LGBTQ individuals who are unable to find evidence of their community's history may experience an increase in minority stress.

In this article, I compare how archivists in mainstream institutions like academic, state, and federal archives apply terminology regarding sexuality and gender diversity when describing materials related to LGBTQ history and individuals to the terms used by members of the LGBTQ community when writing about themselves and their own history. This comparison will reveal how discoverable the archival materials are and whether the descriptions of these archival materials support a positive LGBTQ identity.

To conduct this comparison, I examined LGBTQ history project Web sites from cities in four regions in the United States and one region in Canada for terms the local LGBTQ community uses to describe sexual and gender identity. I then used these terms as keywords when searching for LGBTQ materials in a corresponding mainstream archives in each city. The differences between the terms used show where archivists can improve descriptions of archival materials to make collections easier to find and less likely to contribute to the stigmatization, discrimination, and marginalization of the LGBTQ community.

\section{Literature Review}

\section{BACKGROUND}

In this article, I define "mainstream" or "traditional" archives as being associated with governments, academic institutions, and historical societies. Andrew Flinn, an archivist who strongly advocates for minority inclusion in archives, explained ". . . the mainstream or formal archive sector does not contain and represent the voices of the non-elites, the grassroots, and the marginalized. Or at least if it does, the archive rarely allows them to speak with their voice, through their own records." ${ }^{8}$ In the case of the LGBTQ community, many reasons exist for this dearth of available materials, including the community's ingrained lack of trust in authority.

Historical evidence supports the community's wariness of authority. During the McCarthy era, government officials considered LGBTQ individuals a threat to national security because of the risk of blackmail. Many of these individuals lost their jobs due to the implication that they might be homosexual. In many of these cases, authorities used letters, magazine subscriptions, and police records as evidence to justify their actions. ${ }^{9}$ In an effort to maintain their jobs and professional reputations and to live their lives without stigma, many LGBTQ individuals self-censored when writing letters and in their personal journals. This self-censoring has occurred throughout time. ${ }^{10}$ The families of LGBTQ 
individuals also contributed to this censoring by eliminating any evidence of "nonnormal" sexual practices to protect the memory of their loved ones posthumously. ${ }^{11}$

Another reason why an archives might not have acknowledged LGBTQ materials is the monetary motivation for people to keep quiet about their sexual identities. Rob Hernández, when discussing queer artists of the Chicano/a Art Movement, explained that "[s]uspect sexualities have profound effects on artists' biographies, careers, and art-market valuations and inform the perception of the work." ${ }^{12}$ It was beneficial for these Chicano/a artists to hide any evidence of "deviant" sexual practices while they were alive and for their families to continue this practice after the artists died. Therefore, it could be that materials donated to an archives by an LGBTQ artist or artist's family were never identified with LGBTQ history because of the need to conceal this part of the artist's identity.

Finally, police and court reports along with prison records (jail or mental hospital imprisonment) ${ }^{13}$ are often prolific sources for the study of queer history prior to World War II. When interrogating these police and court reports, researchers should not look for descriptions of individuals as being homosexual, because a state of being is not an actionable offense. Instead, researchers should look for reports detailing the performance or solicitation of deviant sexual practices. Another common accusation was the distribution of pornographic sexual materials. $^{14}$

In an effort to combat the lack of LGBTQ historical materials in mainstream archives, LGBTQ communities created their own archives. The Lesbian Herstory Archive, created by lesbians for lesbians, houses materials anyone can browse as they would for books in a public library. Volunteers from the LGBTQ community appraise, arrange, and describe these materials. The only rule at the Lesbian Herstory Archive is that users leave the materials in a condition that will allow them to be available in the future. ${ }^{15}$ One of the founders of the archives, Joan Nestle, claimed that "[w]e wanted our story told by us, shared by us and preserved by us. We were tired of being the medical, legal, and religious other." ${ }^{16}$ The Lesbian Herstory Archive is one instance of the internal community dialogue created to help support individuals in their sexual identity formation and acceptance journey.

The creation of new community archives boomed during the explosion of LGBTQ activism in the 1970s. During this time, individuals and communities were more likely to save their records for posterity. One reason for this increased interest in the preservation of personal records could have been the creation of the American Library Association's Task Force on Gay Liberation in $1970 .^{17}$ The active support and participation of a national professional organization in the fight for LGBTQ civil rights may have encouraged LGBTQ groups. In 
some cases, when LGBTQ activists were ready to release control of their records, they intentionally chose mainstream archives for the authority they transfer to the records. Tom Hyry and Michelle Light explained this reasoning in their discussion of subjectivity in creating finding aids: "[i]n the very act of soliciting and preserving the records of the underdocumented communities, archivists actively legitimize the experiences of these groups as worthy of remembering and integral to understanding society as a whole." 18 This turn toward deliberately placing LGBTQ materials in traditional archives places the onus on the archivists who work there to make the materials discoverable.

\section{DisCOVERABILITY}

Finding aids for LGBTQ records need to be available to traditional and online-only researchers. Helen Tibbo, in her study of the growing population of online-only researchers, emphasized that these researchers require detailed, easily readable information with little jargon in a writing style more akin to the information in a museum exhibit than that in a traditional archival finding aid. ${ }^{19}$ Because online researchers are more likely to keyword search, access points in the records must include as many of the keywords a researcher might use as possible. Some archives follow the traditional library model of using Library of Congress Subject Headings (LCSH) for separate sets of keyword access points when trying to make finding aids easier for researchers to discover.

However, the Library of Congress does not update these subject headings as quickly as language evolves and terminology usage changes. This results in outdated terms or outdated definitions for the terminology remaining in the LCSH canon. ${ }^{20} \mathrm{~A}$ researcher into LGBTQ history, especially a novice, might use slang language in keyword searches rather than the codified terminology provided by the LCSH and therefore would be less likely to locate records, especially in an unknown item search.

Grant Campbell, in his work on creating archival access tools for gay and lesbian communities, embraces constant shifts in terminology, “. . . people are different, categories shift, and labels are provisional. We are dealing with no monolithic identity, no stable categories, and no consensus . . . survival within a marginalized group depends on the regular and frequent subversion of traditional classification categories." ${ }^{21}$ Archivists who include these varied terms in the descriptions of materials make the materials more discoverable. This discoverability allows members of the LGBTQ community access to their own history and bolsters the survival of the community as a whole. 
HARM

Discoverability is not the only concern when describing archival collections. The question of whether the language used could be harmful to a member of the LGBTQ community must also be considered. By using language incompatible with a person's identity, or terms that an individual may perceive as derogatory or a slur, the description could add to the stigmatization and discrimination an individual feels. This stigmatization can lead to a negative perception of one's minority identity and the psychological consequences, which include depression and self-harm behaviors. ${ }^{22}$ An example of outdated and potentially harmful terminology is the word "homosexuality." When the Library of Congress added "homosexuality" to its list of subject headings, the word was a "see also" term under "sexual perversion." This is no longer the case, but the debate continues over whether "homosexuality," a term created by the medical establishment, correctly represents the group it describes. ${ }^{23}$

In a similar vein, the Library of Congress subject headings "transsexual" or "transgender people" are often used for all gender nonconforming individuals. However, "trans*," "gender queer," or "gender fluid" are the common parlance in the LGBTQ community because these terms convey much of the spectrum of gender expressions. ${ }^{24}$ For example, some catalogers and archivists mistakenly apply the word "transsexual" as a subject heading for any materials related to gender nonconformance. "Transsexual" is a medical diagnosis: a male or female who "is deeply unhappy as a member of the sex (or gender) to which he or she was assigned," and who "has the desire to physically alter their body through surgery and the use of hormones." 25 Therefore, "transsexual" as a subject heading should only apply to materials that fit this strict definition.

Archivists need to be careful to respect the self-identifications of donors of LGBT collections as well. If an archivist solely applies the subject heading "lesbian" when describing a collection, that collection would lose some of its unique history and context. The creator of the collection might have described herself as a "tribade" or "female husband," which would offer an important contextual clue for historians and other researchers. Community members and archivists alike not knowing these terms, or not using them because they might be obscure, is another way in which marginalized societies lose pieces of their history. ${ }^{26}$

Another important aspect to consider is the harm that changes in definition might cause. Modern terms might retain their original spelling, but their definitions could be radically different. Estelle Freedman, in her discussion of the personal papers of Miriam Van Waters (a social activist in the 1950s), described "homosexual" as one such term. Originally a verb used to describe a sexual act, during the 1950s, "homosexual" became a noun used to describe 
a sexual disorder. When that shift occurred, the definition of "homosexual" became a description of a person who was sexually aggressive toward someone of the same sex. This new definition as a psychiatric condition caused psychiatrists and the public to view homosexuality as a "curable social problem not unlike alcoholism." ${ }^{27}$ Using this definition, many people of that time who would acknowledge that they participated in romantic and physical same-sex relationships would not have identified themselves as "homosexuals." Therefore, careful consideration must be given when using this as a subject heading for this collection because it could imply that Van Waters was a homosexual, a term she would never have used to describe her sexual identity.

One of the greatest challenges concerning the potential for harm is that the LGBTQ community does not internally agree on terminology. For instance, some members use the term "queer" to describe all "nonnormal" sexual practices and nonbinary gender identities, ${ }^{28}$ whereas others in the community believe "queer" to be harmful and pejorative. Slang terminology is also a problem because it only appears in small subsets of the community..$^{29}$ Due to these differences of opinion within the LGBTQ community, archivists need to be careful to find the most respectful terms for all involved. ${ }^{30}$

\section{Methodology}

This is an exploratory study to determine if gaps exist between how the LGBTQ community describes its own history and how archivists describe LGBTQ materials in mainstream archival repositories. Archival descriptions of LGBTQ materials that do not match how LGBTQ community members describe their sexual and gender identities reduce the ability of researchers to find these LGBTQ collections and could potentially add to the stigmatization and discrimination that leads minority community members to feel isolation, depression, and internalized homophobia. ${ }^{31}$ In February and March of 2016, I looked at a very small subset of LGBTQ history project Web sites and institutional archives' finding aids and library catalog records; therefore, results will not be statistically significant.

For the purpose of this research, an institutional or mainstream archives is any archives or special collection administered by a university, established historical society, or government organization. An independent archives is any archives, library, or special collection created by a marginalized community without the administrative oversight of an authoritative body.

It is important to note that LGBTQ terminology differs from region to region. I collected data from traditional archives with LGBTQ collections in four regions of the United States and one region in Canada. After I chose the mainstream archives, I looked in that region for an independent archives. If 
multiple independent archives were close to the mainstream archives, I selected the independent archives with the most comprehensive Web site. If there was no independent archives in the region, I chose independent archives closest to the traditional archives.

The four regions of the United States were Northeast, South, Midwest, and West grouped by state according to a map provided by the U.S. Census Bureau. All of Canada was included in the selection process for that region. I used the "Lavender Legacies Guide" created by the Society of American Archivists' Lesbian and Gay Archives Roundtable (LAGAR) ${ }^{32}$ to develop the sampling lists. This guide, while not comprehensive, lists LGBTQ collections in the United States and Canada. Unfortunately, LAGAR has not updated "Lavender Legacies" since 2012, but it still contains a diverse population of traditional archives from which to sample.

For each region, I included all the archives whose LGBTQ collections have online finding aids or detailed catalog entries describing their contents in a list. I generated a random number and chose the mainstream archives that corresponded to the resulting number on the list. Four out of the five archives chosen have subject guides that list the LGBTQ collections in the archives. In the case without a subject guide, I only examined those collections that contained the keywords "LGBT," "gay," "lesbian," "homosexual," "bisexual," or "transgender." Without a subject guide, I was unable to consider older collections that do not use modern terminology to describe the collections.

I searched LGBTQ history projects Web site exhibition pages produced by local LGBTQ archives in the same region as the institutional archives chosen for the study for terms describing sexual and gender identities. I used these terms as keywords to search the traditional archives' finding aids. All the keywords came from photo captions, timelines, and the contextual information provided in the exhibition portions of the Web sites. The exhibition pages in these Web sites provide information about local history derived from the archival collections. The Web sites also provide a point of access for new donors and contributors to add their knowledge and materials to the community's collection.

After compiling a list of keywords from the LGBTQ history Web sites, I used a control + F command (a short cut to start keyword searches when using a PC) to search for these descriptors in the institutional archives' finding aids and library catalog records. Some descriptors I found may offend readers, as these terms were at one time slang that outsiders used to deride and humiliate LGBTQ individuals. The LGBTQ community has repurposed and reinterpreted some of these words to be able to use them in a positive light and remove any harmful connotations that they might have for the future members of the community. These repurposed terms may still cause discomfort and hurt. 


\section{Results}

\section{NORTHEAST}

In the Northeast region, I examined the the History Project-Documenting LGBTQ History in Boston, Massachusetts, ${ }^{33}$ Web site to find the terms used by the community to describe their gender and sexual identities. The History Project maintains its archival holdings independent of an institutional archival repository. Interns from Simmons College's School of Library and Information Science created the finding aids for the History Project. Therefore, I did not look at the finding aids for further terms because it was impossible to determine if the interns themselves were members of the Boston LGBTQ community. I examined the Web site on February 25, 2016. Since that time, the History Project has added more exhibitions, and the acronym "LGBTQ" is now prominently displayed on the Web site, which it was not originally.

I compared the History Project terms to the descriptions of archival materials provided online by the Schlesinger Library on the History of Women in America. ${ }^{34}$ This traditional archives is part of the Radcliffe Institute for Advanced Study at Harvard University. The Schlesinger Library provides an "LGBTQ Research Guide" to its sixty-one LGBTQ archival collections. In this subject guide, the library lists all the collections a researcher of LGBTQ history might find useful with links to either a full finding aid or a detailed library catalog description.

Some of the finding aids do not include any of the keywords listed. These collections seemed to have no reference to the LGBTQ community until I read the biographical descriptions closely. The materials in these collections generally predate or are contemporary to World War II,

Table 1. Usage Count of Keywords from the History Project Also Found in the Schlesinger Library's “LGBTQ Research Guide"35

\begin{tabular}{|c|c|}
\hline Keyword & Usage Count \\
\hline Dyke & 133 \\
\hline Butch & 2 \\
\hline Femme & 3 \\
\hline Lesbian & 619 \\
\hline Gay & 266 \\
\hline Transgender & 89 \\
\hline Transgendered Woman & 2 \\
\hline Transgendered Man & 0 \\
\hline Homosexual & 29 \\
\hline Bisexual & 55 \\
\hline LGBT & 4 \\
\hline Queen & 15 \\
\hline Female Impersonator & 10 \\
\hline Drag Queen & 0 \\
\hline Drag King & 20 \\
\hline Homophile & 1 \\
\hline Transvestite & 18 \\
\hline Transsexual & 41 \\
\hline Fag & 13 \\
\hline Gender Queer & 0 \\
\hline Queer & 20 \\
\hline Fairy & 12 \\
\hline
\end{tabular}


before the upsurge in public discourse about diverse sexualities and genders. The creators of these materials would probably not have used any of the descriptors gleaned from the History Project Web site to describe themselves. Instead, the biographies include subtle hints. For example, the finding aid for the Mary Ellicott Arnold Papers (1908-1958) describes a female "life-long companion" but does not indicate that this woman was a lesbian. ${ }^{36} \mathrm{~A}$ researcher who did not know about the LGBT subject guide might not have found the Mary Ellicott Arnold Papers or other collections like it.

The finding aids that contain terms that could be offensive, like "dyke," did not use these keywords as part of the description provided by the archivist. The offensive terms, and some of the slang, all appear in the inventory as folder or content labels. In this way, the LGBTQ community is describing itself through the materials that they donated. "Dyke" appears so often because it was part of a magazine title, and the collection contained many such magazines. If these detailed content lists had not been available, unique descriptors would not have appeared.

In one collection it seems like an error was made in pronoun usage in a description of one of the collections. The J. Ari. Kane-Demaios Papers includes a biographical note that seems to use the wrong gender pronoun throughout the description. Ariadne Kane was born Joseph DeMaios but had since transitioned. The finding aid refers to her with male pronouns. However, Ariadne Kane identifies as a female, therefore, it seems like the description should refer to Ariadne Kane with female pronouns. ${ }^{37}$

\section{MidWest}

In the Midwest region, I looked at the Wisconsin LGBT History Project ${ }^{38}$ Web site. The Web site presents general information about LGBTQ history, but has a clear historical focus on the Milwaukee area. The archival materials collected by the history project are housed at the University of Wisconsin. The Web site makes a point to mention that the exhibition curators tried to use terms that match the periods of time they were describing. Earlier materials would exclusively use terms like "gay" and "lesbian." Further along in the timeline, I encountered terms like "bisexual" and "transgender" as well as many slang variants of more common descriptors.

The traditional archives I selected was the Wisconsin Historical Society ${ }^{39}$ based in Madison, Wisconsin, which has no subject guide for LGBTQ collections. So, first I searched all the Wisconsin Historical Society's holdings to find LGBTQ references in finding aids and located twenty-two collections. I then searched within the resulting finding aids for other keywords on the list. The LGBTQ community rarely created the collections I found using this method. Many of 
the finding aids had only one or two folders in the entire collection relevant to LGBTQ history and identity.

I noticed an interesting dichotomy regarding the context surrounding these keywords. One finding aid that had a strong connection to LGBTQ community history used "dyke" and "queer" only once. When these words did appear, it was as examples of particularly harmful terms used to describe members of the LGBTQ community. Another finding aid used "queer" liberally without any implication that the term might be hurtful.

\section{SOUTH}

In the South, I explored the Rainbow History Project ${ }^{41}$ Web site. Historians in the District of Columbia who are members of the LGBTQ community created this archives. These scholars were unable to find the materials they needed to research their own history in traditional settings, so they created their own repository. The project started in 2000 and has since grown to include a diverse set of exhibitions and timelines chronicling the many different aspects of LGBTQ history.

The archival materials collected by the Rainbow History Project are housed at an institution, but all the content on the Web site is created and curated by volunteers. The tone of the information is educational, and curators carefully chose all exhibition items to match this tone. While slang is sometimes used, the Web site mostly uses a diverse set of descriptors for a limited number of gender and sexual identities.

I compared the keywords I found on the history project Web site to the finding aid and library catalog descriptions provided by George Washington University $^{42}$ for its thirteen LGBTQ collections. In this instance, there was a subject guide available to help me find the collections. 
The George Washington University finding aids employ the terms "gay" or "lesbian" almost exclusively, with few instances of more specific terminology. One of the timelines the Rainbow History Project created focuses solely on the history of the trans* community and uses a diversity of terms such as "Male-To-Female," "Transgendered Woman," and "Transwoman." In the thirteen George Washington collections, terms used to describe the trans* community only appear three times. In each of these cases, an archivist used these descriptors in conjunction with the terms "lesbian," "gay," and "bisexual" when spelling out acronyms.

As with the Midwest's traditional archival collections, one specific finding aid at George Washington uses the terms "dyke" and "faggot" only to make the point that they should never be used to describe an individual. It seems that the archivists at George Washington University used the keywords "gay" and "lesbian" as all-encompassing terminology to describe the LGBTQ community. The LGBTQ community used these descriptors in the past, but now, in an effort to acknowledge the wide spectrum of identities that make up the entire LGBTQ world, the community describes materials more often either as specifically as possible, or at least as "lesbian," "gay," "bisexual," and "transgender."

A unique aspect of the George Washington University finding aids is the use of specific Library of Congress Subject Headings. These finding aids include more than the general subject headings "Lesbianism," "Homosexual," and similar commonly used access points. One in particular is "Gay and

Table 3. Usage Count for Keywords from the Rainbow History Project Also Found in the Collections Included in the George Washington University Subject Guide for LGBT Collections

\begin{tabular}{|l|c|}
\hline \multicolumn{1}{|c|}{ Keyword } & Usage Count \\
\hline Homosexual & 9 \\
\hline Gay & 470 \\
\hline Lesbian & 217 \\
\hline Same-sex & 2 \\
\hline Drag Queen & 3 \\
\hline Bisexual & 13 \\
\hline LGBT & 3 \\
\hline Queer & 11 \\
\hline Faggot (Fag) & 2 \\
\hline Transgendered & 3 \\
\hline Two-Spirited & 0 \\
\hline Queen & 0 \\
\hline Transsexual & 0 \\
\hline Cross Dresser & 0 \\
\hline LGBTQ & 0 \\
\hline Female-To-Male & 0 \\
\hline Transman & 0 \\
\hline Intersex & 0 \\
\hline Transwoman & 0 \\
\hline Transmasculine & 0 \\
\hline Transgender Woman & 0 \\
\hline Male-To-Female & 0 \\
\hline Pansy & 0 \\
\hline Female Impersonator & 0 \\
\hline Homophile & 0 \\
\hline GLBT & 0 \\
\hline Dyke & 0 \\
\hline
\end{tabular}


Lesbian-Poets." These sub-subject headings can help researchers find the materials they need more easily.

WEST

The independent archives I examined in the West was the Colorado LGBT History Project ${ }^{43}$ curated by the Center, the largest LGBT community center in the Rocky Mountain region. It opened in 1976 and has a rich history of activism and support for the LGBTQ community. The Colorado LGBT History Project Web site was still under construction, so it offered far fewer exhibitions to examine in my effort to compile a keyword list. The available information showed that the history project focuses on the Denver LGBTQ community and its influence on the Rocky Mountain region.

The mainstream archives I looked at was the Stephen $\mathrm{H}$. Hart Library, ${ }^{44}$ which provides access to History Colorado collections. History Colorado provides a subject guide that includes seventeen archival collections deemed applicable to the research of LGBTQ history. However, all that was available to search were the library catalog entries as none of the finding aids are available online.

The information provided in the library catalog entries conform to an older standard of description when "gay" and "lesbian" were the terms used to describe the entire community. "Gay" appeared more

Table 4. Usage Count of Keywords from the Colorado LGBT History Project Also Found in the Collections Included in the History Colorado Subject Guide of LGBT Materials ${ }^{45}$

\begin{tabular}{|l|c|}
\hline \multicolumn{1}{|c|}{ Keyword } & Usage Count \\
\hline LGBT & 0 \\
\hline Lesbian & 33 \\
\hline Gay & 66 \\
\hline Bisexual & 0 \\
\hline Transgender & 0 \\
\hline GLBT & 2 \\
\hline LGBTQ & 0 \\
\hline Same-sex & 0 \\
\hline Cross Dressing & 0 \\
\hline Homosexual & 9 \\
\hline Drag Queen & 0 \\
\hline Homophile & 0 \\
\hline
\end{tabular}
often because the community used the word "gay" in the past to describe all members of the LGBTQ community. These descriptions most frequently use the term "homosexual" not as part of the archivist-generated content but as a Library of Congress Subject Heading. Other indicators that these descriptions follow an older standard is the use of the acronym "GLBT" and the fact that the term "transgender" does not appear in any of the catalog entries. For a significant portion of LGBTQ history, viewing transgender issues as a distinct subgroup needing its own terminology and the addressing of its specific issues separately from lesbian and gay activism was disfavored. ${ }^{46}$ 


\section{CANADA}

The Canadian independent archives I examined was the Canadian Lesbian and Gay Archives (CLGA). ${ }^{47}$ This archives collects materials from the entirety of Canada, not just a specific region. CLGA, like the ONE National Gay and Lesbian Archives at the University of Southern California, began as a magazine, which was known as The Body Politic. The creators of this magazine preemptively collected materials from its readers while the magazine was still being published in an effort to create a community-focused archives to provide references and resources for future members of the Canadian LGBTQ community.

The CLGA claims to be the largest collection of LGBTQ materials in the world. However, unlike many of the other independent archives I have reviewed, the CLGA houses, describes, and provides access to its materials independent of any institutional support. In an effort to compile the keyword list, I examined all of the descriptions for future, current, and past exhibitions of LGBTQ materials. Interestingly, the descriptions on the CLGA Web site imply that "queer" is the all-encompassing term used in Canada to describe the entire LGBTQ community.

I compared the descriptors from CLGA to the nine archival collections available at the Transgender Archives housed at the University of Victoria. ${ }^{48}$ The creators of the Transgender Archives wanted to document the history of the transgender community in isolation from the larger LGBTQ community. Aaron H. Devor and Lara Wilson explained the mission, history, and current projects of the Transgender Archives in "Putting Trans* History on the Shelves: The Transgender Archives at the University of Victoria, Canada." ${ }^{49}$ Devor and Wilson described the archives as having “. . . approximately 320 linear feet [of material] ... the collection includes materials

Table 5. Usage Count of Keywords from the Canadian Lesbian and Gay Archives Also Found in the Collections Listed as Archival Materials in the Transgender Archives at the University of Victoria ${ }^{52}$

\begin{tabular}{|l|c|}
\hline \multicolumn{1}{|c|}{ Keyword } & Usage Count \\
\hline Lesbian & 2 \\
\hline Gay & 4 \\
\hline Transgender & 54 \\
\hline LGBTQ+ & 0 \\
\hline Queer & 0 \\
\hline Butch & 0 \\
\hline Sissy & 1 \\
\hline Fairy & 0 \\
\hline Cross Dresser & 16 \\
\hline Transsexual & 26 \\
\hline LGBT & 0 \\
\hline LGBTQ & 1 \\
\hline Drag Queen & 0 \\
\hline Genderqueer & 0 \\
\hline Transmen & 2 \\
\hline Female-To-Male & 1 \\
\hline Drag King & 0 \\
\hline Femme & 0 \\
\hline Dyke & \\
\hline Same Sex & 0 \\
\hline
\end{tabular}


from seventeen countries, with research materials going back more than one hundred years and activist records going back more than fifty years." 50 There is also a mention of " . . . over 800 books, including many rare, hard-to-find, and first editions; an extensive collection of informational pamphlets and booklets, generally produced by advocacy organizations for educational purposes. . . "51

The Transgender Archives Web site provides small descriptions of each collection with only a few collections having separate finding aids. Only one finding aid has a full description of the collection; the others only include a content list. It is interesting to note that the descriptions provided by the archives heavily favor the more traditional terms "transsexual" and "transgender," with very little slang or specific terminology to describe different members of the trans* community. The most used slang term is "Cross Dresser." This archives appears to still be in its infancy. It will be interesting to review it in a few years to examine the difference between the current descriptions and those added in the future.

\section{Findings}

Across all of the different regions, the most frequently used descriptor by the institutional archives is "gay." Besides the term "gay," the most common terms found were general descriptors like "lesbian," "homosexual," "bisexual," and "transgender." "Transsexual" appears when describing transgender materials because that is the Library of Congress Subject Heading often assigned to those materials.

Some evidence supports my original supposition that terminology would differ in different regions of the country. In a majority of the collections across all regions, the slang terms and some of the more specialized terminology does not appear in any of the finding aids or catalog descriptions. Specialized slang that does appear in finding aids is part of the folder name or appears in titles of publications found in the collections. I did not find any instance where the institutional archives uses a term not used by the curators of the independent archival Web site.

The lack of LGBTQ community-developed descriptors in finding aids reduces the potential for LGBTQ community members to access their own history. This lack of access adds to the existing marginalization, discrimination, and stigmatization of LGBTQ individuals. Heidi Reyst, in her doctoral dissertation on the acculturation of LGBTQ individuals, stressed that "collective community history" is crucial for the identity development of new community members. ${ }^{53}$ A lack of community history could set back LGBTQ individuals who are trying to accept this new part of their identities. Delayed acceptance reduces the social interaction an individual has with the larger LGBTQ community. Social interaction is imperative because it helps to ameliorate the psychological consequences, such as depression and anxiety, of being part of a social minority. ${ }^{54}$ 


\section{Conclusion}

To continue to improve the descriptions of LGBTQ materials, the next avenue of research could be to investigate those mainstream archives that already collaborate with local LGBTQ communities when developing descriptions of these materials. An in-depth investigation into these collaborations could produce a model to help archivists create relationships with their own local LGBTQ communities. This model may be generalized to provide a way for archivists to collaborate with all marginalized communities without having to expend too many new resources.

After exploring the different LGBTQ history project Web sites and those of corresponding traditional archives, I suggest the following steps for institutional archivists to consider when describing LGBTQ collections. While I recognize resources for archives are often scarce, it is important to take steps to provide better descriptions for and better access to collections.

First, archivists arranging and describing these collections could do an in-depth interview with the donor or a local LGBTQ community member for a deeper understanding of the materials. This interview should include a specific discussion about terminology. In collaborating with LGBTQ community members, archivists will learn the community-specific terminology. This will help prevent archivists from applying a catchall term like "transgender" to materials that require a more nuanced description, thus reducing the potential harm these finding aids could cause to members of the LGBTQ community. ${ }^{55}$

Second, archivists could create subject or keyword access points for all records. These access points should not be limited to the Library of Congress Subject Headings. A section titled "Related Topics" or "Keyword Access" could be included in finding aids to list as many of the terms that a researcher might use to find the records as possible. This is especially important for older materials or for materials whose creators deliberately refused to use labels to describe themselves. This new section would not retroactively identify these individuals as members of the LGBTQ community; instead, it would provide an access point for researchers to find these collections. I recommend that in the finding aid's biographical note, historical note, and content description sections, archivists should use the original, historically accurate terminology if known.

Third, researchers could have some forum to provide additional information, and, if necessary, corrections to the finding aids. A statement could be included in each finding aid to solicit corrections and additional contextual information. This would be especially important for older collections. We, as archivists, do not often have the time to go back to old finding aids to look for errors unless users make these errors clear. This would also allow archivists and researchers to share the burden, responsibility, and authority of description. 
I do not advocate that these corrections be unmediated by the archivist. Ultimately, the archivists are responsible for what users see, so additional information provided by researchers should be fact checked and approved before it appears publicly on an institution's Web site. The library cataloging community is exploring this practice by allowing users to create folksonomies and tags to help shape descriptions. These folksonomies evolve and change as languages changes, but the collection retains all the legacy tags as well. ${ }^{56}$

In light of the difficulty of constantly changing vocabularies and the lack of resources most institutions have for going back over older descriptions, another solution could be for traditional archives to create subject guides or annotated bibliographies of their LGBTQ materials. This would allow archivists to concentrate on updating one document instead of constantly reviewing finding aids as language changes.

I believe these suggestions will help make collections easier to access and reduce the potential for harm to LGBTQ community members. The increase in access would develop out of the ability of researchers to use current terminology as keywords to discover archival collections. Incorporating language created by the LGBTQ community to describe themselves would give them more agency in how archivists present their history, thereby combating marginalization, stigmatization, and discrimination and leading to a greater sense of community self-esteem and well-being.

\section{Notes}

1 Diane L. Zosky and Robert Alberts, "What's in a Name? Exploring Use of the Word Queer as a Term of Identification within the College-Aged LGBT Community," Journal of Human Behavior in the Social Environment 26, nos.7-8 (2016): 597-607.; and Michele J. Eliason, "An Exploration of Terminology Related to Sexuality and Gender: Arguments for Standardizating the Language," Social Work in Public Health 29, no. 2 (2014): 162-75.

2 In this article, I use the acronym LGBTQ(Lesbian, Gay, Bisexual, Transgender, Queer). I do so because the current, most comprehensive acronym is long, with some terms missing or interchangeable depending on where the acronym appears. The most inclusive acronym is LGBTQQIP2SAA (Lesbian, Gay, Bisexual, Transgender, Queer, Questioning, Intersex, Pansexual, Two-spirit, Asexual, Allies). A shorter variant of this is being seen more and more as LGBTQ (Lesbian, Gay, Bisexual, Transgender, Queer) or LGBTQIA (Lesbian, Gay, Bisexual, Transgender, Queer, Intersex, Asexual).

3 A caveat for "queer" is that the social majority has been using this term since the 1940s as a slur to humiliate and degrade all persons assumed not to conform to Western society's sexuality and gender norms. So, while many in the LGBT community identify as "queer," not all members of the community are able to do so. Zosky and Alberts, "What's in a Name?"

4 Zosky and Alberts, "What's in a Name?"

5 Ilan H. Meyer, "Prejudice and Discrimination as Social Stressors," in The Health of Sexual Minorities: Public Health Perspectives on Lesbian, Gay, Bisexual and Transgender Populations, ed. Ilan H. Meyer and Mary E. Northridge (New York: Springer Science and Business Media LLC, 2007), 245.

${ }^{6}$ Meyer, "Prejudice and Discrimination as Social Stressors," 245. 
7 Michelle Caswell, Alda Allina Migoni, Noah Geraci, and Marika Cifor, “'To Be Able to Imagine Otherwise': Community Archives and the Importance of Representation," Archives and Records (2016), doi:10.1080/23257962.2016.1260445.

8 Andrew Flinn, "Community Histories, Community Archives: Some Opportunities and Challenges," Journal of the Society of Archivists 28, no. 2 (2007): 151-76, 152.

9 Craig M. Loftin, "Secrets in Boxes: The Historian as Archivist," in Out of the Closet, Into the Archives: Researching Sexual Histories, ed. Amy L. Stone and Jamie Cantrell (Albany: State University of New York Press, 2015), 51-63.

${ }^{10}$ Estelle B. Freedman, “The Burning of Letters Continues': Elusive Identities and the Historical Construction of Sexuality," in Modern American Queer History, ed. Allida M. Black (Philadelphia: Temple University Press, 2001), 51-68.

${ }^{11}$ Loftin, "Secrets in Boxes."

${ }^{12}$ Robb Hernández, "Straight Talk, Queer Haunt: The Paranormal Activity of the Chicano Art Movement," in Out of the Closet, Into the Archives, 175-204.

${ }^{13}$ Steven Maynard, “The Burning, Wilful Evidence': Lesbian/Gay History and Archival Research,” Archivaria 33 (Winter 1991): 195-202; Steven Maynard, "Police/Archives," in "Special Section on Queer Archives," special issue, Archivaria 68 (Fall 2009): 159-82; and K. J. Rawson, "Accessing Transgender // Desiring Queer(er?) Archival Logics," in "Special Section on Queer Archives," special issue, Archivaria 68 (Fall 2009): 123-40. The special issue was Archivaria 68.

${ }^{14}$ Diane Beattie, "Retrieving the Irretrievable: Providing Access to 'Hidden Groups' in Archives," The Reference Librarians 26, no. 56 (1997): 83-94.

${ }^{15}$ Agatha Beins, "Making a Place for Lesbian Life at the Lesbian Herstory Archives," in Out of the Closet, Into the Archives, 25-49.

${ }^{16}$ Julie R. Enszer, "Feverishly Lesbian-Feminist: Archival Objects and Queer Desires," in Out of the Closet, Into the Archives, 149-71, 152.

${ }^{17}$ Melissa Adler, “'Let's Not Homosexualize the Library Stacks': Liberating Gays in the Library Catalog," Journal of the History of Sexuality 24, no. 3 (2015): 478-507.

${ }^{18}$ Michelle Light and Tom Hyry, "Colophones and Annotations: New Directions for the Finding Aid," The American Archivist 65, no. 2 (2002): 216-30, 219.

${ }^{19}$ Amanda Hill, "Serving the Invisible Researcher: Meeting the Needs of Online Users," Journal of the Society of Archivists 25, no. 2 (2004): 139-48.

${ }^{20}$ Sanford Berman, Prejudice and Antipathies: A Tract on the LC Subject Heads Concerning People (Metuchen, N.J.: Scarecrow Press, Inc., 1971).

${ }^{21}$ Grant Campbell, "Queer Theory and the Creation of Contextual Subject Access Tools for Gay and Lesbian Communities,” Knowledge Organization 27, no. 3 (2000): 122-31, 127.

${ }^{22}$ Deborrah E. S. Frable, Camille Wortman, and Jill Joseph, "Predicting Self-Esteem, Well-Being, and Distress in a Cohort of Gay Men: The Importance of Cultural Stigma, Personal Visibility, Community Networks, and Positive Identity,” Journal of Personality 65, no. 3 (1997): 599-624.

${ }^{23}$ Michael Buckland, "Obsolescence in Subject Description," Journal of Documentation 68, no. 2 (2012):154-61.

${ }^{24}$ Zosky and Alberts, "What's in a Name?,"602-5.

${ }^{25}$ Liam Oliver Lair, "Interrogating Trans* Identities in the Archives," in Out of the Closet, Into the Archives, 233-54, 242.

${ }^{26}$ Melissa Adler, "For Sexual Perversion See Paraphilias: Disciplining Sexual Deviance at the Library of Congress” (PhD diss., University of Wisconsin-Madison, 2012), 194.

${ }^{27}$ Freedman, “The Burning of Letters Continues," 57.

${ }^{28}$ Adler, "For Sexual Perversion See Paraphilias," 198.

${ }^{29}$ Campbell, "Queer Theory and the Creation."

${ }^{30}$ Campbell, "Queer Theory and the Creation."

${ }^{31}$ Marcia Ash and Catherine J. Mackereth, "Assessing the Mental Health and Well-Being of the Lesbian, Gay, Bisexual and Transgender Population," Community Practitioner 86, no. 3 (2013): 24-27. 
${ }^{32}$ Society of American Archivists, “Lavender Legacies Guide," http:/|www2.archivists.org/groups/ lesbian-and-gay-archives-roundtable-lagar/lavender-legacies-guide.

${ }^{33}$ The History Project-Documenting LGBTQ Boston, http://www.historyproject.org/, February 2016.

${ }^{34}$ The Arthur and Elizabeth Schlesinger Library on the History of Women in America, https://www. radcliffe.harvard.edu/schlesinger-library, February 2016.

${ }^{35}$ I examined the Schlesinger Library's finding aids and library catalog records in February 2016.

${ }^{36}$ Mary Ellicott Arnold Papers, 1908-1958; finding aid, Schlesinger Library, Radcliffe Institute, Harvard University, Cambridge, Mass., http://oasis.lib.harvard.edu/oasis/primo?id=sch00217.

${ }^{37}$ J. Ari Kane-DeMaios Papers, 1970-2005; finding aid, Schlesinger Library, Radcliffe Institute, Harvard University, Cambridge, Mass., http://oasis.lib.harvard.edu/oasis/primo?id=sch01269.

${ }^{38}$ Wisconsin LGBT History Project, http://www.mkelgbthist.org/, March 2016.

${ }^{39}$ Wisconsin Historical Society, https://www.wisconsinhistory.org/, March 2016.

${ }^{40}$ I examined the Wisconsin LGBT History Project Web site and the Wisconsin Historical Society finding aids and library catalog records in March 2016.

${ }^{41}$ The Rainbow History Project, http://rainbowhistory.org/, March 2016.

${ }^{42}$ George Washington Libraries Finding Aids by Topic: LGBT, https://library.gwu.edu/scrc/search/ finding-aids-by-topic/lgbt, March 2016

${ }^{43}$ Colorado LGBT History Project, http://glbtcolorado.org/colorado-lgbt-history-project/, March 2016.

${ }^{44}$ Stephen H. Hart Library and Research Center, http://legacy.historycolorado.org/researchers/ stephen-h-hart-library-and-research-center, March 2016.

${ }^{45}$ I examined the Colorado LGBT History Project Web site and the History Colorado finding aids and library catalog records in March 2016.

${ }^{46}$ Aaron H. Devor and Lara Wilson, "Putting Trans* History on the Shelves," in Out of the Closet, Into the Archives, 255-67, 256.

47 Canadian Lesbian and Gay Archives, https://clga.ca/, March 2017.

${ }^{48}$ University of Victoria Transgender Archives, https://www.uvic.ca/transgenderarchives/, March 2017.

49 Devor and Wilson, "Putting Trans* History on the Shelves."

${ }^{50}$ Devor and Wilson, "Putting Trans* History on the Shelves," 257.

${ }^{51}$ Devor and Wilson, "Putting Trans* History on the Shelves," 259.

${ }^{52}$ I examined the Canadian Lesbian and Gay Archives exhibition Web sites and the University of Victoria Transgender Archives finding aids in March 2016.

${ }^{53}$ Heidi Elizabeth Reyst, “Gay and Lesbian Acculturation: Behavioral and Psychological Consequences” (PhD diss., George Washington University, 2001).

${ }^{54}$ Reyst, “Gay and Lesbian Acculturation,” 20.

${ }^{55}$ Rawson, "Accessing Transgender."

${ }^{56}$ Melissa Adler, "Transcending Library Catalogs: A Comparative Study of Controlled Terms in Library of Congress Subject Headings and User-Generated Tags in LibraryThing for Transgender Books," Journal of Web Librarianship 3, no. 4 (2009): 309-31.

\section{ABOUT THE AUTHOR}

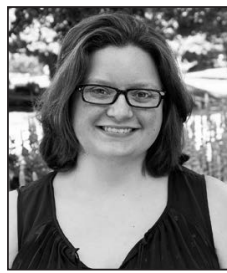

Erin Baucom is the assistant professor and the digital archivist at the University of Montana. She earned her master's degree in library science with a concentration in archives and records management from the University of North Carolina at Chapel Hill in 2016. She holds a BA in history from Old Dominion University. Her major research interests include the history of technology, how archivists describe the records of marginalized groups, and how to make born-digital records accessible. 